\title{
Incidental detection, imaging modalities and temporal trends of differentiated thyroid cancer in Ontario: a population-based retrospective cohort study
}

\author{
Todd A. Norwood MSA, Emmalin Buajitti MPH, Lorraine L. Lipscombe MD, Thérèse A. Stukel PhD, \\ Laura C. Rosella PhD
}

Abstract

Background: Incidence rates of thyroid cancer in Ontario have increased more rapidly than those of any other cancer, whereas mortality rates have remained relatively stable. We evaluated the extent to which incidental detection of differentiated thyroid cancer during unrelated prediagnostic imaging procedures contributed to Ontario's incidence rates.

Methods: We conducted a retrospective cohort study involving Ontarians who received a diagnosis of differentiated thyroid cancer from 1998 to 2017 using linked health care administrative databases. We classified cases as incidentally detected if a nonthyroid diagnostic imaging test (e.g., computed tomography [CT]) preceded an index event (e.g., prediagnostic fine-needle aspiration biopsy); all other cases were nonincidentally detected cases. We used Joinpoint and negative binomial regressions to characterize sex-specific rates of differentiated thyroid cancer by incidentally detected status and to quantify potential age, diagnosis period and birth cohort effects.

Results: The study included 36531 patients with differentiated thyroid cancer, of which $78.7 \%$ were female. Incidentally detected cases increased from $7.0 \%$ to $11.0 \%$ of female patients and from $13.5 \%$ to $18.2 \%$ of male patients over the study period. Agestandardized incidence rates increased more rapidly for incidentally detected cases (4.2-fold for female and 3.7-fold for male patients) than for nonincidentally detected cases (2.6-fold for female and 3.0-fold for male patients; $p<0.001$ ). Diagnosis period was the primary factor associated with increased incidence rates of differentiated thyroid cancer, adjusting for other factors. Within each period, incidentally detected rates increased faster than nonincidentally detected rates, adjusting for age. Our results showed that CT was the most common imaging procedure preceding incidentally detected diagnoses.

Interpretation: Incidentally detected cases represent a large and increasing component of the observed increases in differentiated thyroid cancer in Ontario over the past 20 years, and CT scans are primarily associated with these cases despite the modality having similar, increasing rates of use compared with magnetic resonance imaging (1993-2004). Recent increases in rates of differentiated thyroid cancer among males and incidentally detected cases among females in Ontario appear to be unrelated to birth cohort effects.

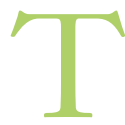
here is debate and concern about a worldwide epidemic of thyroid cancer overdiagnosis. ${ }^{1,2}$ Several factors suggest that a large reservoir of indolent thyroid cancers is being detected by sensitive imaging techniques. Incidence rates of thyroid cancer are increasing worldwide in every continent except Africa, whereas mortality rates from thyroid cancer are low and relatively stable. ${ }^{3-5}$ Large increases in the registrations of differentiated thyroid cancers $\left(\geq 90 \%\right.$ of thyroid cancer cases $\left.^{6}\right)$ and subclinical microcarcinomas $(\leq 1.0 \mathrm{~cm}$ in diameter; $50 \%$ of thyroid cancers in America $^{7}$ ) have paralleled increases in the availability and use of sensitive imaging techniques, concomitant with increased incidence rates. ${ }^{8-10}$ Further, autopsy studies show a large potential reservoir of occult thyroid cancers awaiting diagnostic scrutiny. ${ }^{11}$

Nonetheless, increases in thyroid cancer may also be related to aging populations, ${ }^{12,13}$ use of ionizing radiation (a risk factor for thyroid cancer) to treat benign conditions between the 1930 s and $1960 \mathrm{~s}^{14}$ and changes in environmental or lifestyle factors. ${ }^{15,16}$ Increases in larger, clinically detectable thyroid cancers ${ }^{17,18}$ and recent increases in thyroid cancer mortality rates $^{15,19}$ support such hypotheses. Such factors that counter the prevailing overdiagnosis hypothesis exist in Canada. . $^{13,18,20}$

Diagnostic imaging may lead to thyroid cancer diagnosis during investigations for conditions unrelated to the thyroid

Competing interests: Todd Norwood reports grants from the Canadian Institutes of Health Research, during the conduct of the study. No other competing interests were declared.

This article has been peer reviewed.

Correspondence to: Todd Norwood, todd.norwood@mail.utoronto.ca

CMAJ Open 2020. DOI:10.9778/cmajo.20200095 
(denoted as incidentally detected) or through screening tests (e.g., ultrasonography) for thyroid cancer in asymptomatic persons (screen-detected). ${ }^{8,21,22}$ We conducted a study to evaluate the extent to which advanced diagnostic imaging procedures were associated with observed increases in incidence rates of differentiated thyroid cancer in Ontario. The objectives were to classify differentiated thyroid cancers detected among Ontario patients who received a diagnosis from 1998 to 2017 as incidentally detected or not, based on the pathway to diagnosis, and to assess sex-specific incidence rate trends by incidentally detected status and imaging modality.

\section{Methods}

\section{Study design and setting}

We conducted a retrospective cohort study involving Ontario residents who received a diagnosis of differentiated thyroid cancer from 1998 to 2017. Patient records were linked using unique encoded identifiers and analyzed at ICES, an institution with legal status to collect and analyze health care-related data for health system evaluation and improvement.

\section{Data sources}

Multiple health administrative databases for publicly insured hospital and physician services were used: the Ontario Cancer Registry for incident cases of differentiated thyroid cancer; the Ontario Health Insurance Plan (OHIP) for physician billings, which includes diagnosis codes and procedures; the Discharge Abstract Database for hospital admissions and procedures; and the Registered Persons Database for patient demographic information and population estimates (Appendix 1, Supplementary Table 1, available at www.cmajopen.ca/ content/8/4/E695/suppl/DC1). These data sets are of high quality (Appendix 1, Supplementary Table 1). ${ }^{23-26}$

\section{Study population}

Using the Ontario Cancer Registry, we identified an initial cohort of patients with differentiated thyroid cancer, using the International Agency for Research on Cancer multiple primary rules, ${ }^{27}$ and linked to the other databases to determine exclusion criteria and examine diagnostic pathways. We included patients aged 15 to 84 years because there were fewer patients in the youngest and oldest age categories. The age range was selected to maximize the number of eligible patients as thyroid cancer is the most common cancer among Ontarians aged 15-29 years $^{20}$ and diagnostic imaging use increases with age. ${ }^{28,29}$ We excluded patients with prior cancers (Ontario Cancer Registry), 2 or more inpatient high-dose ionizing radiation scans in any year more than 1 year before diagnosis of differentiated thyroid cancer (Discharge Abstract Database) and those with a history of bone marrow transplant (Discharge Abstract Database; Appendix 1, Supplementary Figure 1). Patients were followed up to Mar. 31, 2018. Appendix 1, Supplemental Tables 2-6 and Appendix 2 (available at www.cmajopen.ca/content/8/4/E695/suppl/DC1) provide all codes used to identify the study population and procedures.

\section{Exposure}

We used American Thyroid Association clinical practice guidelines (1996-2015), wherein fine-needle aspiration biopsy is the recommended ${ }^{30-33}$ gold-standard procedure for thyroid nodule evaluation, ${ }^{31,34}$ to classify differentiated thyroid cancer diagnosis as incidentally detected or not, by examining diagnostic pathways using OHIP billings (Appendix 1, Supplementary Figure 2). Advanced diagnostic imaging modalities such as computed tomography (CT) and magnetic resonance imaging (MRI) are not recommended in the guidelines for thyroid cancer diagnostic purposes. ${ }^{30-33}$

For each patient who received a diagnosis of differentiated thyroid cancer, the index study date was defined as date of prediagnostic thyroid gland aspiration, core or fine-needle biopsy ("thyroid biopsy"). When thyroid biopsy was not ascertained, the date of differentiated thyroid cancer diagnosis was used as the index date. The index study date then initiated a look-back period to determine whether the differentiated thyroid cancer was incidentally detected. An incidentally detected case was defined as a scan of 1 or more of carotid ultrasonography, CT, MRI, positron emission tomography (PET), or single-photon emission CT to the head, neck or thorax within 3 months before study index date. PET scans were involved in few cases $(<10)$ and excluded from imaging modality-specific analyses. Patients with multiple imaging modalities within the look-back period were assigned the first modality.

A 3-month look-back period was selected a priori based on clinical expertise and Ontario institutional evidence (fineneedle aspiration biopsy wait time, 2009-2011: mean 80.7 days [95\% confidence interval 78.7-82.6]; range 50-90 days ${ }^{35}$ ).

\section{Covariates}

Five-year age range at diagnosis (15-19 to 80-84), 5-year diagnosis period (1998-2002 to 2013-2017) and 10-year birth cohort at diagnosis (1913-1922 to 1993-2002) groups were defined as these variables were expected to influence differentiated thyroid cancer rates. ${ }^{8-10,12-14}$

\section{Outcomes}

We evaluated sex-specific rates of differentiated thyroid cancer cases by incidentally detected status. Annual age-standardized (2011 Canadian population ${ }^{36}$ ) incidence rates were computed using the Registered Persons Database population.

\section{Statistical analysis}

To describe age-standardized rate trends, we used Joinpoint regression, which identifies statistically significant changes in trends by fitting Monte Carlo permutations of models with and without temporal change points to improve model fit. ${ }^{37}$ Change points were determined by fitting up to 3 internal points between 2000 and 2015 using a grid-search method to select those that improved fit according to hypothesis testing $(p<0.05)$. We used negative binomial regression to quantify differentiated thyroid cancer rates by incidentally detected status and for incidentally detected cases, by imaging modality, to disentangle potential age, diagnosis period and birth 
cohort effects. For these analyses, we used multivariable ageperiod-cohort regression models that included terms for age, diagnostic period, birth cohort groups and an offset term for population. ${ }^{38}$ For incidentally detected-specific models, an imaging modality by diagnostic period interaction term was included to evaluate imaging modality changes over time. For the look-back period, sensitivity analyses were conducted using 2-, 4-, 6-, 9- and 12-month look-back periods.

Since birth cohort is uniquely defined by age and diagnosis period, which causes a statistical identifiability problem, we imposed a constraint for the full age-period-cohort models. We used information on medical use of ionizing radiation procedures for benign conditions in Canada $(1930-1960)^{14}$ to define an appropriate birth cohort constraint, which set the 1918-1927 estimate equal to the 1923-1932 estimate; in sensitivity analyses, we used an approach that does not impose a constraint. ${ }^{39}$

Among nested models, likelihood ratio tests were used to select the optimal fit for age-period-cohort covariates and their subsets. The Akaike information criterion was used to select the optimal fit for non-nested models.

We evaluated plots of standardized residuals, leverage and influential observations for all regression models. SAS 9.4 (SAS Institute Inc.) "genmod" and Stata Statistical Software: Release 15 (StataCorp) "nbreg" and "apc_cglim" procedures were used to fit statistical models. All statistical tests were performed at the $5 \%$ level of significance and were 2 -sided.

\section{Ethics approval}

The University of Toronto Research Ethics Board (protocol ID 36626) approved this study.

\section{Results}

A total of 36531 patients with differentiated thyroid cancer were included in the study (Table 1). Most patients (28 735, $78.7 \%$ ) were female. Incidentally detected cases among female patients (2680) outnumbered those among male patients (1314), but the proportion among male patients (16.9\%) was nearly double that of female patients $(9.3 \%)$. Incidentally detected cases increased from $7.0 \%$ to $11.0 \%$ among female patients and from $13.5 \%$ to $18.2 \%$ among male patients from the 1998-2002 to 2013-2017 periods. The proportion of histologically confirmed (i.e., biopsy-proven) cases was near complete (about 97\%) and did not vary by incidentally detected status. Incidentally detected case patients were older, and the rates increased more rapidly in each diagnosis period compared with nonincidentally detected rates. Computed tomography was the dominant imaging modality for incidentally detected cases ( $>65 \%$ of cases).

\section{Descriptive trends}

Over the study period, age-standardized incidence rates increased significantly for both nonincidentally detected and incidentally detected cases, although rates decreased after 2013 for nonincidentally detected cases in female patients, based on Joinpoint analysis (Figure 1 and Appendix 1,
Supplementary Tables 7-8). For each sex, absolute rates were higher for nonincidentally detected cases than for incidentally detected cases, but rates increased relatively more for incidentally detected cases (4.2-fold for female patients and 3.7-fold for male patients) than for nonincidentally detected cases (2.6-fold for female patients and 3.0-fold for male patients) (Appendix 1, Supplementary Table 7).

By birth cohort, age-specific incidence rates of nonincidentally detected cases showed peaks in the fifth and sixth decades of life with evidence of potential effects from age, birth cohort and diagnosis period among female and male patients (Figure 2, panels $\mathrm{A}$ and $\mathrm{B}$ ). For incidentally detected cases, age-specific rates by birth cohort show sustained rates in older ages for each sex, and lower potential cohort or period effects for male patients (Figure 2, panels $\mathrm{C}$ and D).

By diagnosis period, age-specific incidence rates of nonincidentally detected cases show marked increases by the period between 1998 and 2012 among female and male patients, and a potential period effect in the most recent period (compared with 2008-2012) for male patients only (Figure 3, panels A and B). By diagnosis period, incidentally detected case age-specific rates also show marked, potential diagnosis period effects, sustained to older ages ( $\geq 60 \mathrm{yr}$ ) for each sex compared with nonincidentally detected rates (Figure 3, panels $\mathrm{C}$ and D).

\section{Model-based adjusted rates}

We evaluated regression models to test the adjusted effects of age, diagnosis period and birth cohort. For nonincidentally detected cases among female patients, age, period and cohort produced the optimal fit; for the other models, age and period produced the optimal fit (Appendix 1, Supplementary Table 9). For incidentally detected case-specific models that evaluated imaging modality, age-period models with a modality-period interaction term provided optimal fit.

The adjusted model-based rate ratios indicate that diagnosis period was most strongly associated with increases in the rate of differentiated thyroid cancer, exceeding twofold in the last 2 diagnosis periods (Table 2). However, increases associated with diagnosis period were larger for incidentally detected rates than nonincidentally detected rates, exceeding threefold in 2013-2017. Adjusted incidentally detected rates decreased significantly with younger age $(<45 \mathrm{yr})$ and peaked in older ages (e.g., male patients ages 65-74 yr) compared with nonincidentally detected rates that peaked in ages 50-64.

Incidentally detected case-specific imaging modality models show that CT was the primary modality associated with increased rates (Table 3). For example, for the 1998-2002 diagnosis period, rates associated with the other modalities were $81 \%$ to $98 \%$ lower than those associated with CT. In addition, incidentally detected rates associated with MRI increased about twofold among female patients and fivefold among male patients at each diagnosis period compared with 1998-2002.

\section{Sensitivity analyses}

Although the proportion of incidentally detected cases increased with longer look-back period (from 9.3\% to $19.3 \%$ and from $16.9 \%$ to $30.5 \%$ for female and male patients, 
Research

Table 1: Characteristics of patients with differentiated thyroid cancer ( $n=36531$ ) by sex and pathway to diagnosis (incidentally detected v. nonincidentally detected), Ontario, $1998-2017^{*} \dagger$

\begin{tabular}{|c|c|c|c|c|}
\hline \multirow[b]{2}{*}{ Characteristic } & \multicolumn{2}{|c|}{$\begin{array}{c}\text { Female patients } \\
n=28735 ; 78.7 \% \text { of patients }\end{array}$} & \multicolumn{2}{|c|}{$\begin{array}{c}\text { Male patients } \\
n=7796 ; 21.3 \% \text { of patients }\end{array}$} \\
\hline & $\begin{array}{c}\text { Incidentally detected; } \\
\text { no. }(\%) \ddagger\end{array}$ & $\begin{array}{c}\text { Nonincidentally detected; } \\
\text { no. }(\%) \ddagger\end{array}$ & $\begin{array}{c}\text { Incidentally detected; } \\
\text { no. }(\%) \ddagger\end{array}$ & $\begin{array}{c}\text { Nonincidentally detected; } \\
\text { no. }(\%) \ddagger\end{array}$ \\
\hline Total & $2680(9.3)$ & 26055 (90.7) & 1314 (16.9) & $6482(83.1)$ \\
\hline \multicolumn{5}{|l|}{ Age, yr } \\
\hline $15-29$ & $170(6.3)$ & $2596(10.0)$ & $67(5.1)$ & $540(8.3)$ \\
\hline $30-49$ & $954(35.6)$ & $12563(48.2)$ & $406(30.9)$ & $2627(40.5)$ \\
\hline $50-69$ & 1166 (43.5) & $9288(35.6)$ & $623(47.4)$ & 2755 (42.5) \\
\hline $70-84$ & $390(14.6)$ & $1608(6.1)$ & $218(16.6)$ & $560(8.6)$ \\
\hline Mean \pm SD & $52.7 \pm 15.0$ & $47.0 \pm 13.7$ & $54.7 \pm 14.5$ & $49.7 \pm 14.0$ \\
\hline \multicolumn{5}{|l|}{ Diagnosis period } \\
\hline 1998-2002 & 247 (9.2) & 3301 (12.6) & $128(9.7)$ & $818(12.6)$ \\
\hline 2003-2007 & $494(18.4)$ & $5599(21.4)$ & $232(17.6)$ & $1261(19.4)$ \\
\hline 2008-2012 & $843(31.4)$ & $8271(31.7)$ & $405(30.8)$ & 1941 (29.9) \\
\hline 2013-2017 & $1096(40.9)$ & $8884(34.1)$ & $549(41.7)$ & $2462(38.0)$ \\
\hline \multicolumn{5}{|l|}{ Birth cohort } \\
\hline $1913-1922$ & $7(0.2)$ & $26(0.1)$ & $-^{\star \star}$ & $12(0.2)$ \\
\hline 1918-1927 & $24(0.9)$ & $98(0.3)$ & $16(1.2)$ & $38(0.6)$ \\
\hline 1923-1932 & $74(2.7)$ & $255(1.0)$ & $44(3.3)$ & $90(1.4)$ \\
\hline 1928-1937 & $120(4.4)$ & $516(2.0)$ & $71(5.4)$ & $191(2.9)$ \\
\hline $1933-1942$ & $181(6.7)$ & $899(3.4)$ & $83(6.3)$ & $282(4.3)$ \\
\hline $1938-1947$ & $215(8.0)$ & $1366(5.2)$ & $123(9.3)$ & $451(6.9)$ \\
\hline 1943-1952 & $288(10.7)$ & $2086(8.0)$ & $173(13.1)$ & $655(10.1)$ \\
\hline $1948-1957$ & $284(10.6)$ & 2707 (10.4) & $164(12.4)$ & $765(11.8)$ \\
\hline 1953-1962 & 330 (12.3) & 3358 (12.9) & $146(11.1)$ & $833(12.8)$ \\
\hline 1958-1967 & 327 (12.2) & $3816(14.6)$ & $145(11.0)$ & 879 (13.5) \\
\hline $1963-1972$ & $281(10.5)$ & 3379 (12.9) & $112(8.5)$ & 751 (11.6) \\
\hline $1968-1977$ & $202(7.5)$ & $2832(10.8)$ & $101(7.6)$ & $564(8.7)$ \\
\hline 1973-1982 & $144(5.3)$ & $2104(8.0)$ & $59(4.5)$ & $422(6.5)$ \\
\hline $1978-1987$ & $108(4.0)$ & $1434(5.5)$ & $36(2.7)$ & $272(4.2)$ \\
\hline 1983-1992 & $62(2.3)$ & $723(2.7)$ & $21(1.6)$ & $170(2.6)$ \\
\hline $1988-1997$ & $24(0.9)$ & $352(1.3)$ & $15(1.1)$ & $81(1.2)$ \\
\hline $1993-2002$ & $9(0.3)$ & $104(0.4)$ & $-{ }^{\star \star}$ & $26(0.4)$ \\
\hline Alive & $2428(90.6)$ & $25162(96.5)$ & $1094(83.2)$ & $6035(93.1)$ \\
\hline Histologically confirmed & $2598(96.9)$ & $25325(97.2)$ & $1279(97.3)$ & $6321(97.5)$ \\
\hline $\begin{array}{l}\text { Thyroid biopsy } \leq 6 \text { mo before } \\
\text { diagnosis date§ }\end{array}$ & $1609(60.0)$ & $16813(64.5)$ & $765(58.2)$ & $4220(65.1)$ \\
\hline \multicolumn{5}{|l|}{ Imaging modality } \\
\hline CT & $1760(65.6)$ & NA & $960(73.0)$ & NA \\
\hline Carotid ultrasonography & $275(10.2)$ & NA & $115(8.7)$ & NA \\
\hline MRI & $290(10.8)$ & NA & $95(7.2)$ & NA \\
\hline SPECT & $355(13.2)$ & NA & $140(10.6)$ & NA \\
\hline \multicolumn{5}{|c|}{ 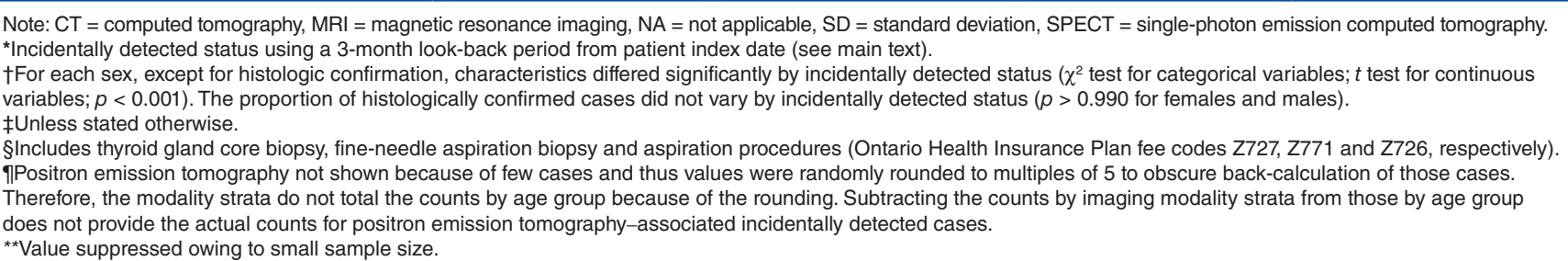 } \\
\hline
\end{tabular}




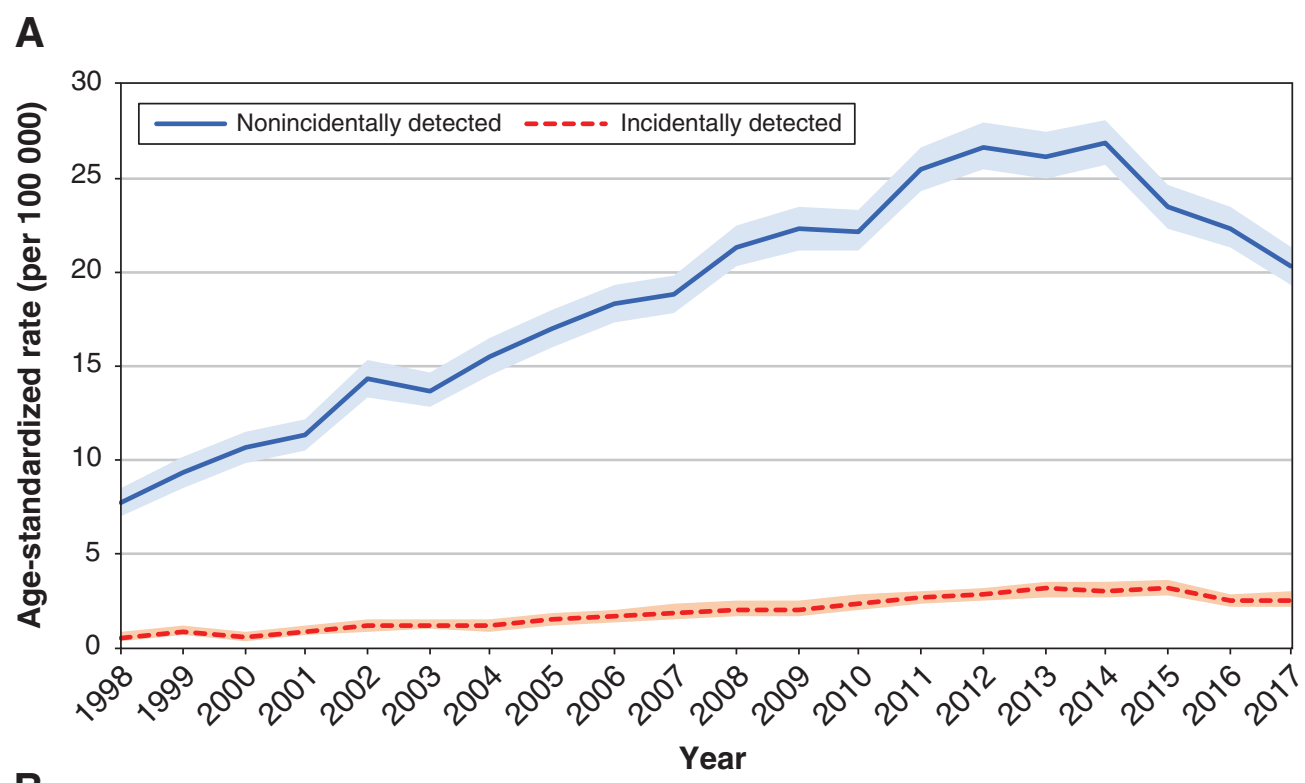

B

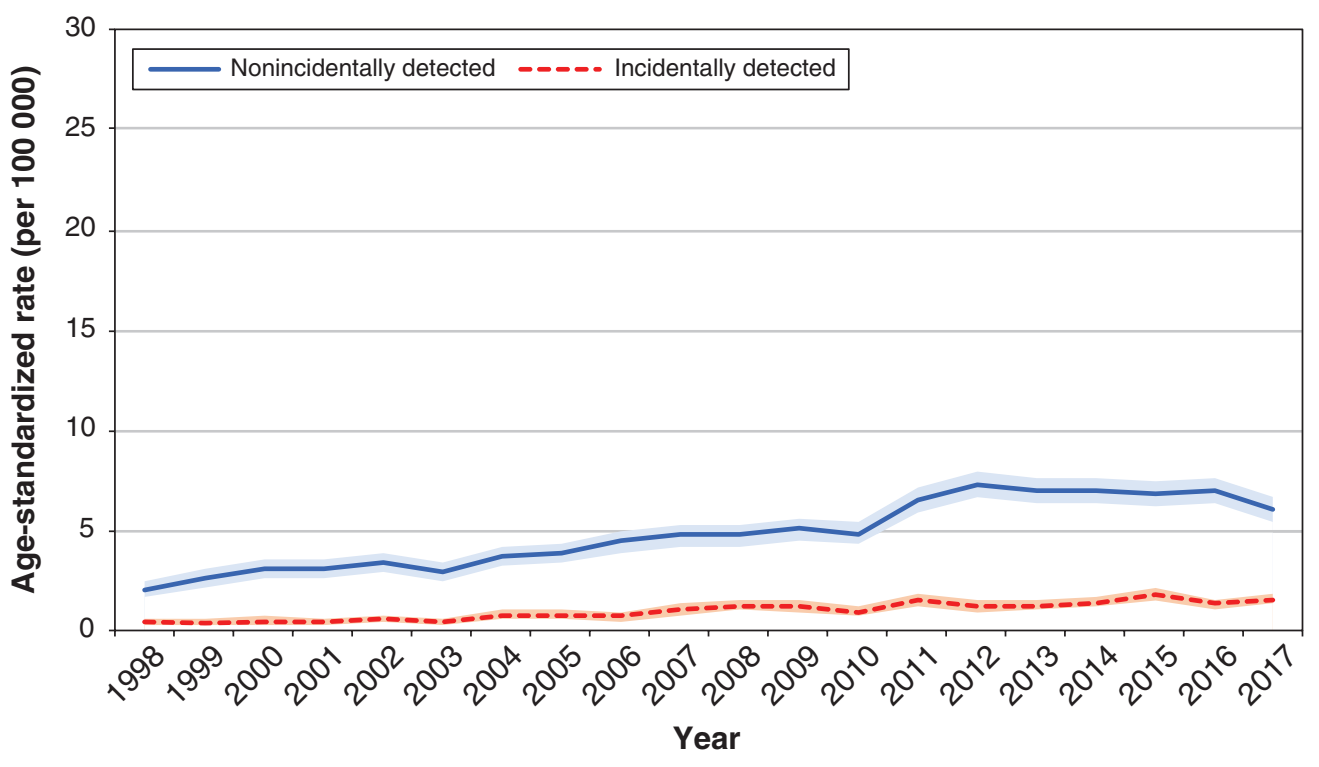

Figure 1: Differentiated thyroid cancer age-standardized incidence rates (per 100000 person-years) by sex and incidentally detected status, 1998-2017. Restricted to patients aged 15 to 84 years at diagnosis. Rates are age-standardized to people registered with an Ontario health card (Registered Persons Database). The shaded bands indicate the $95 \%$ confidence intervals for the rates. (A) Female age-standardized rates by incidentally detected status. (B) Male age-standardized rates by incidentally detected status.

respectively), patients with incidentally detected cases were consistently older (Appendix 1, Supplementary Table 10). Trends in age-specific rates by birth cohort or diagnosis period were not sensitive to look-back period (Appendix 1, Supplementary Figures 3-6). Model selection was not sensitive to look-back period, and the parameter estimates were consistent (Appendix 3, available at www.cmajopen.ca/ content/8/4/E695/suppl/DC1). Use of the birth cohort constraint did not affect the results (Appendix 4, available at www.cmajopen.ca/content/8/4/E695/suppl/DC1).

\section{Interpretation}

The incidence of differentiated thyroid cancer has increased rapidly over the past 20 years in Ontario. We found that incidentally detected cases represent up to $20 \%$ and $30 \%$ of differentiated thyroid cancer cases among female and male patients in Ontario, respectively. These increases were seen after accounting for age at diagnosis and birth cohort. Incidence rates of incidentally detected cases are increasing faster than rates of nonincidentally detected cases among 


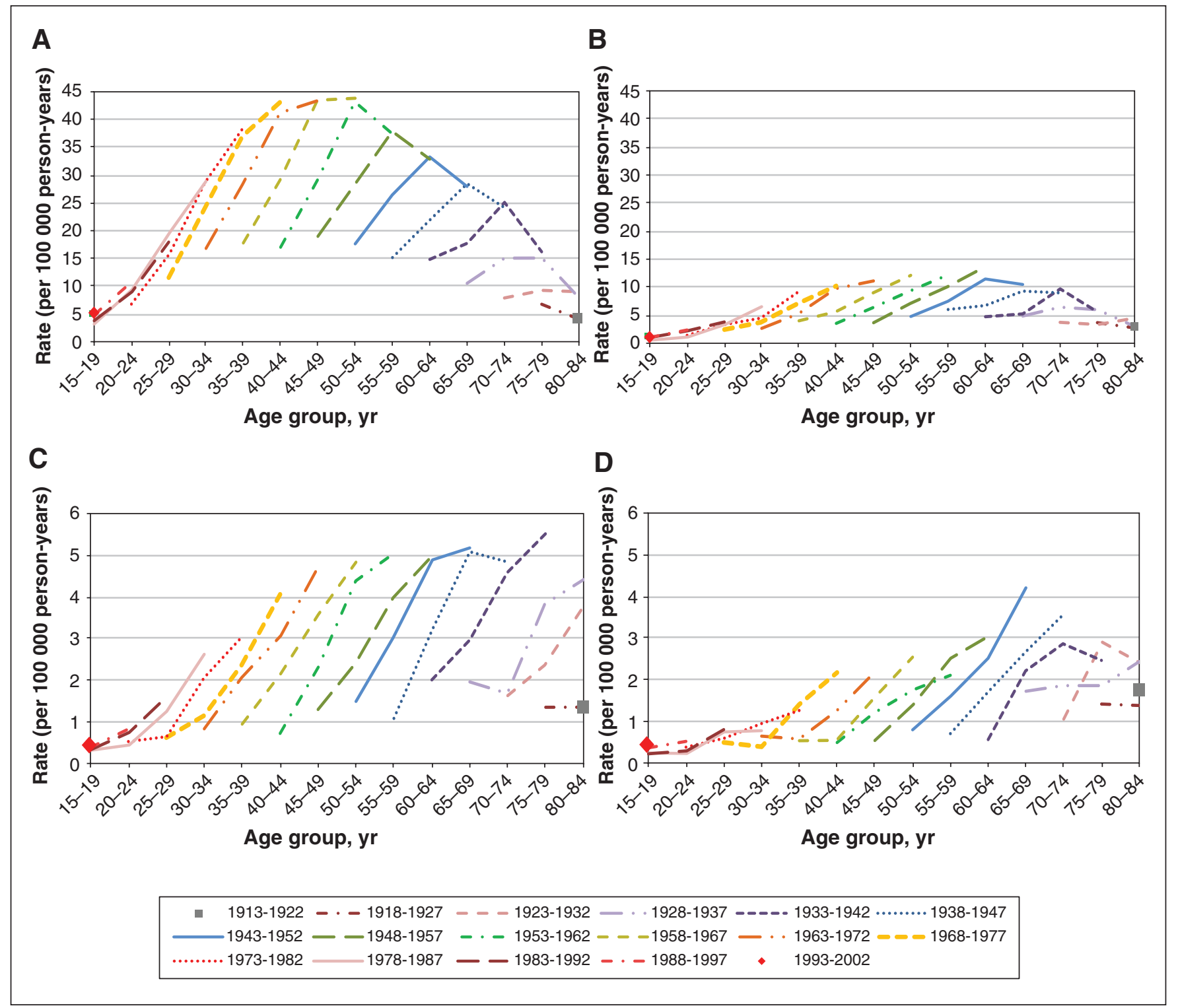

Figure 2: Differentiated thyroid cancer age-specific rates (per 100000 person-years) by birth cohort and sex for nonincidentally detected cases (panels A and B) and incidentally detected cases (panels C and D). Restricted to patients aged 15 to 84 years at diagnosis. These descriptive results do not disentangle potential age, diagnosis period or birth cohort effects. (A) Female age-specific rates by birth cohort, nonincidentally detected cases. (B) Male age-specific rates by birth cohort, nonincidentally detected cases. (C) Female age-specific rates by birth cohort, incidentally detected cases. (D) Male age-specific rates by birth cohort, incidentally detected cases.

female and male patients, and CT- and MRI-associated incidentally detected rates have increased significantly.

This population-based study examined diagnostic pathways to classify patients with differentiated thyroid cancer according to incidentally detected status defined by primary care practice guidelines from the American Thyroid Association ${ }^{30-33}$ and quantified population-based trends in differentiated thyroid cancer rates by status and imaging modality relevant to the North American setting. The recent decline in rates among female patients in Ontario is consistent with the trend in the United States ${ }^{19}$ and may reflect the 2015 guideline discouraging evaluation of subcentimetre thyroid nodules. ${ }^{33}$ Although the pre-2009 guidelines did not provide size-based nodule recommendations for fine-needle aspiration biopsy, ${ }^{31}$ the 2015 guideline added recent, evidence-based sonographic characteristics for malignancy assessment and nodule size to the evaluation algorithm, wherein biopsy was not recommended for subcentimetre nodules. ${ }^{33}$ By design, to reduce iatrogenic exposures, we excluded patients with multiple inpatient CT scans, nuclear imaging or procedures involving ionizing radiation exposure that are higher dose than conventional radiography $y^{40}$ prior to a differentiated thyroid cancer diagnosis.

An American single-institution study that assessed the Society of Radiologists in Ultrasound guideline found that $15 \%$ of cases were incidentally detected over 10 years without considering diagnostic pathways beyond ultrasonography. ${ }^{21}$ 


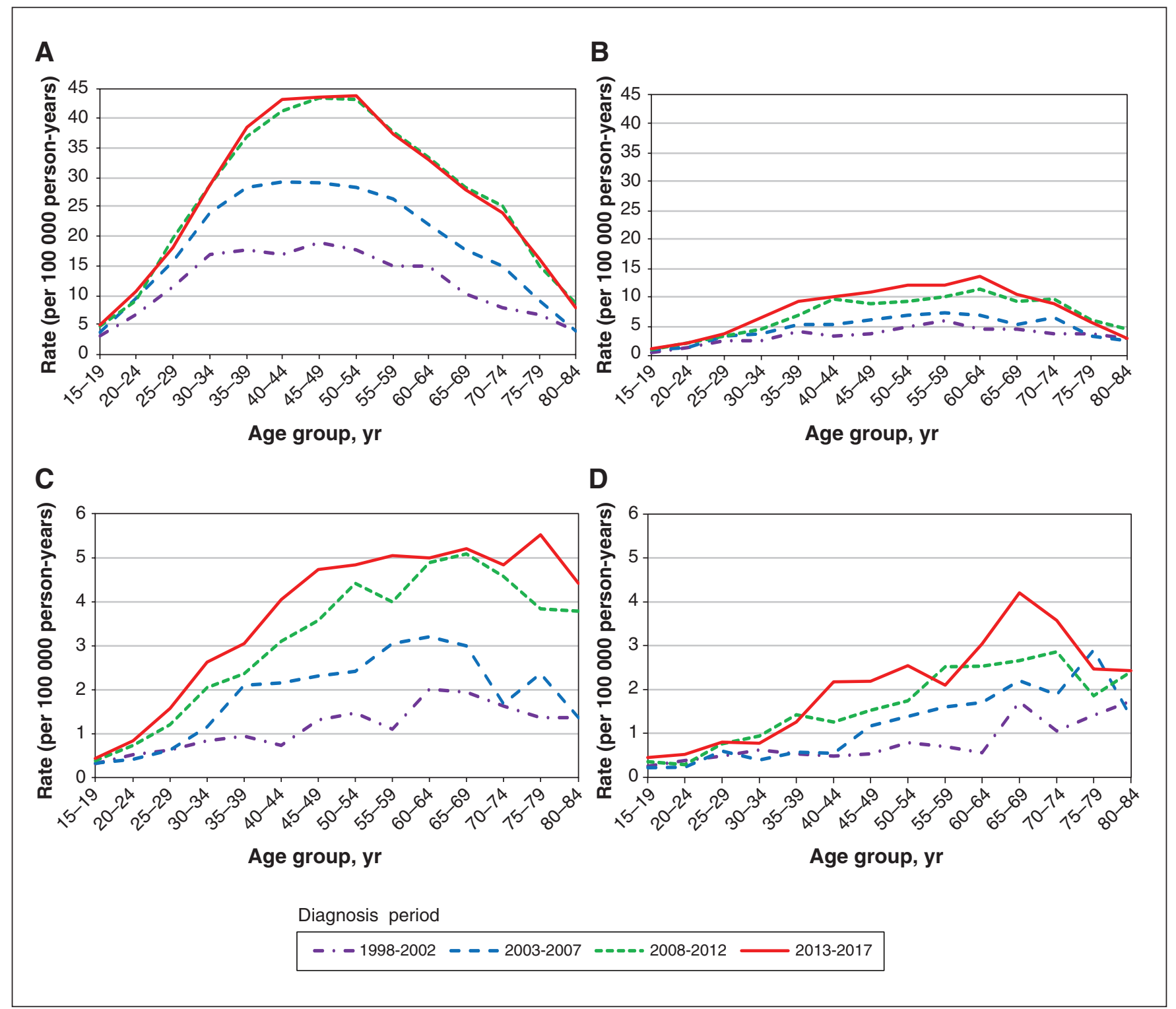

Figure 3: Differentiated thyroid cancer age-specific rates (per 100000 person-years) by diagnosis period and sex for nonincidentally detected cases (panels A and B) and incidentally detected cases (panels $C$ and D). Restricted to patients aged 15 to 84 years at diagnosis. These descriptive results do not disentangle potential age, diagnosis period or birth cohort effects. (A) Female age-specific rates by diagnosis period, nonincidentally detected cases. (B) Male age-specific rates by diagnosis period, nonincidentally detected cases. (C) Female age-specific rates by diagnosis period, incidentally detected cases. (D) Male age-specific rates by diagnosis period, incidentally detected cases.

A Japanese study examined the routes to thyroid cancer detection, and similarly, found increasing rates of incidentally detected thyroid cancer, even exceeding nonincidentally detected thyroid cancer found in patients older than age 44 years, using cases detected by screening, health checkups and follow-up of other diseases to define incidentally detected cancer. ${ }^{41}$

Our finding of age-period-cohort effects for nonincidentally detected case rates in female patients is consistent with prior thyroid cancer findings in Canada from 1970 to $1996 .{ }^{14}$ Earlier American and Canadian studies of thyroid cancer incidence trends up to the mid-1990s reported declining or stabilizing birth cohort effects overall, ${ }^{42}$ and for male patients specifically, ${ }^{14}$ but this effect was not evident among male patients in our study. In addition, our study may not have identified birth cohort effects for men given shorter life expectancy than women.

Our study shows that incidentally detected cases increasingly contribute to rising differentiated thyroid cancer rates, concomitant with increased availability and use of CT and MRI in Ontario. ${ }^{43}$ However, CT units have outnumbered other imaging modalities in Ontario (e.g., 2012, 168 CTs v. 104 $\left.\mathrm{MRIs}^{43}\right)$, had the highest per capital use rate of the imaging modalities (e.g., in 2012, 12.5 CT, 7.7 MRI and 0.7 PET-CT scans per 1 million people ${ }^{43}$ ), and are associated with provincial increases in rates of incidentally detected differentiated thyroid cancer. 


\begin{tabular}{|c|c|c|c|c|}
\hline \multirow[b]{2}{*}{ Covariate } & \multicolumn{2}{|c|}{$\begin{array}{l}\text { Female patients; rate ratio }(95 \% \mathrm{Cl}) \\
\qquad n=28735\end{array}$} & \multicolumn{2}{|c|}{$\begin{array}{l}\text { Male patients; rate ratio }(95 \% \mathrm{Cl}) \\
\qquad n=7796\end{array}$} \\
\hline & $\begin{array}{l}\text { Nonincidentally } \\
\text { detected† } \\
n=26055\end{array}$ & $\begin{array}{l}\text { Incidentally detected } \\
\quad n=2680\end{array}$ & $\begin{array}{l}\text { Nonincidentally } \\
\text { detected } \\
n=6482\end{array}$ & $\begin{array}{l}\text { Incidentally detected } \\
\quad n=1314\end{array}$ \\
\hline \multicolumn{5}{|l|}{ Age group, yr } \\
\hline $15-19$ & $0.23(0.04-1.22)$ & $0.09(0.06-0.14)$ & $0.11(0.09-0.14)$ & $0.06(0.03-0.12)$ \\
\hline $20-24$ & $0.44(0.10-1.83)$ & $0.17(0.13-0.23)$ & $0.22(0.19-0.26)$ & $0.13(0.08-0.21)$ \\
\hline $25-29$ & $0.68(0.21-2.25)$ & $0.31(0.25-0.39)$ & $0.38(0.34-0.44)$ & $0.26(0.19-0.37)$ \\
\hline $30-34$ & $0.90(0.35-2.33)$ & $0.51(0.42-0.61)$ & $0.53(0.47-0.59)$ & $0.38(0.28-0.52)$ \\
\hline 35-39 & $1.01(0.49-2.07)$ & $0.64(0.54-0.76)$ & $0.77(0.70-0.86)$ & $0.55(0.43-0.71)$ \\
\hline $40-44$ & $1.02(0.63-1.65)$ & $0.77(0.65-0.90)$ & $0.87(0.79-0.96)$ & $0.69(0.54-0.87)$ \\
\hline $45-49$ & $1.03(0.80-1.31)$ & $0.89(0.76-1.03)$ & $0.91(0.82-1.00)$ & $0.83(0.66-1.04)$ \\
\hline $50-54$ & Referent & Referent & Referent & Referent \\
\hline $55-59$ & $0.87(0.68-1.11)$ & $1.01(0.86-1.18)$ & $1.06(0.96-1.17)$ & $1.06(0.85-1.32)$ \\
\hline $60-64$ & $0.75(0.46-1.21)$ & $1.13(0.96-1.32)$ & $1.12(1.01-1.23)$ & $1.23(0.99-1.54)$ \\
\hline $65-69$ & $0.62(0.30-1.27)$ & $1.14(0.97-1.35)$ & $0.90(0.81-1.01)$ & $1.61(1.29-2.00)$ \\
\hline $70-74$ & $0.54(0.21-1.41)$ & $0.97(0.81-1.17)$ & $0.86(0.76-0.98)$ & $1.45(1.14-1.85)$ \\
\hline $75-79$ & $0.36(0.11-1.18)$ & $1.00(0.82-1.22)$ & $0.56(0.47-0.66)$ & $1.23(0.93-1.62)$ \\
\hline $80-84$ & $0.19(0.05-0.80)$ & $0.82(0.65-1.03)$ & $0.37(0.29-0.46)$ & $1.04(0.74-1.47)$ \\
\hline \multicolumn{5}{|c|}{ Diagnosis period } \\
\hline 1998-2002 & Referent & Referent & Referent & Referent \\
\hline 2003-2007 & $1.60(1.26-2.04)$ & $1.80(1.55-2.10)$ & $1.39(1.27-1.52)$ & $1.62(1.30-2.01)$ \\
\hline 2008-2012 & 2.35 (1.46-3.77) & $2.88(2.50-3.32)$ & $2.03(1.87-2.20)$ & $2.62(2.14-3.19)$ \\
\hline 2013-2017 & $2.49(1.22-5.08)$ & $3.45(3.00-3.96)$ & $2.38(2.20-2.58)$ & $3.21(2.65-3.90)$ \\
\hline \multicolumn{5}{|c|}{$\begin{array}{l}\text { Note: } \mathrm{Cl}=\text { confidence interval. } \\
\text { *Estimates are for the 3-month look-back period; Appendix } 3 \text { (Supplementary Tables 1-4; available at www.cmajopen.ca/content/8/4/E695/suppl/DC1) } \\
\text { provides estimates for each look-back period. } \\
\text { †Female nonincidentally detected statistical model includes birth cohort parameter estimates, which are nonsignificant owing to the constraint } \\
\text { imposed (birth cohort parameter 1918-1927 =1923-1932). Complete coefficients are provided in Appendix } 3 \text { (Supplementary Table 1). }\end{array}$} \\
\hline
\end{tabular}

\section{Limitations}

In using administrative databases, a primary study limitation is our inability to classify incidentally detected differentiated thyroid cancer as overdiagnosis, a concern regarding clinical implications and bias. For clinical implications, the incidentally detected classification requires external validation and examination of patient clinicopathological characteristics, treatment pathways and outcomes to appropriately assess overdiagnosis. For example, we were unable to stratify analyses using pathology characteristics (e.g., tumour size). ${ }^{44}$ Pathology information would help evaluate potential patient and system impacts associated with incidentally detected cases; overtreatment is a major concern because standard therapy involves surgical resection and has substantial morbidities. ${ }^{45-49}$ For our study, overdiagnosis bias would underestimate incidental detection as some differentiated thyroid cancers were likely discovered by neck ultrasonography performed for other indications. Further, our definition of incidentally detected excludes differentiated thyroid cancers detected by thyroid ultrasonography screening, consistent with the US Preventive Services Task Force's recommendation against population-based thyroid cancer screening because of treatment harms and potential for substantial overdiagnosis and overtreatment. ${ }^{50}$ To assume that incidentally detected cases comprise the breadth of overdiagnoses and that nonincidentally detected rate increases evidence, a true increase in differentiated thyroid cancer incidence would be too simplistic.

Our classification of incidental detection is based on diagnostic pathways that were clinically informed but not externally validated. For incidentally detected cases, older age at diagnosis versus nonincidentally detected cases and higher male versus female rates provides face-validity for the classification, as use of diagnostic imaging increases with age, ${ }^{28,29}$ and men aged 60 years and older had the highest rate of combined CT, MRI and ultrasonography tests in Ontario 


\begin{tabular}{|c|c|c|}
\hline Covariate & $\begin{array}{l}\text { Female patients; rate ratio } \\
\qquad \begin{array}{c}(95 \% \mathrm{Cl}) \\
n=2680 \dagger\end{array}\end{array}$ & $\begin{array}{c}\text { Male patients; rate ratio } \\
(95 \% \mathrm{Cl}) \\
n=1314 \dagger\end{array}$ \\
\hline \multicolumn{3}{|l|}{ Imaging modality } \\
\hline $\mathrm{CT}$ & Referent & Referent \\
\hline Carotid ultrasonography & $0.15(0.10-0.23)$ & $0.19(0.12-0.32)$ \\
\hline MRI & $0.08(0.05-0.14)$ & $0.02(0.01-0.09)$ \\
\hline SPECT & $0.16(0.11-0.24)$ & $0.15(0.08-0.26)$ \\
\hline \multicolumn{3}{|l|}{ Age group, yr } \\
\hline $15-19$ & $0.09(0.06-0.14)$ & $0.06(0.03-0.12)$ \\
\hline $20-24$ & $0.17(0.13-0.23)$ & $0.13(0.08-0.21)$ \\
\hline $25-29$ & $0.31(0.25-0.39)$ & $0.26(0.19-0.37)$ \\
\hline $30-34$ & $0.50(0.42-0.61)$ & $0.38(0.28-0.52)$ \\
\hline $35-39$ & $0.64(0.54-0.76)$ & $0.55(0.43-0.71)$ \\
\hline $40-44$ & $0.77(0.65-0.90)$ & $0.69(0.54-0.87)$ \\
\hline $45-49$ & $0.89(0.76-1.03)$ & $0.83(0.66-1.04)$ \\
\hline $50-54$ & Referent & Referent \\
\hline $55-59$ & $1.01(0.86-1.18)$ & $1.06(0.85-1.32)$ \\
\hline $60-64$ & $1.13(0.96-1.32)$ & $1.23(0.99-1.54)$ \\
\hline $65-69$ & $1.14(0.97-1.35)$ & $1.60(1.28-1.99)$ \\
\hline $70-74$ & $0.97(0.81-1.17)$ & $1.46(1.14-1.85)$ \\
\hline $75-79$ & $1.00(0.82-1.22)$ & $1.23(0.93-1.62)$ \\
\hline $80-84$ & $0.82(0.65-1.03)$ & $1.04(0.74-1.47)$ \\
\hline \multicolumn{3}{|l|}{ Diagnosis period } \\
\hline 1998-2002 & Referent & Referent \\
\hline 2003-2007 & $1.56(1.30-1.88)$ & $1.53(1.18-1.97)$ \\
\hline 2008-2012 & $2.61(2.20-3.09)$ & $2.59(2.05-3.26)$ \\
\hline 2013-2017 & $3.20(2.71-3.77)$ & $3.31(2.64-4.14)$ \\
\hline \multicolumn{3}{|l|}{ Modality (period) $\ddagger$} \\
\hline Carotid ultrasonography (2003-2007)§ & $1.26(0.77-2.07)$ & $0.62(0.31-1.23)$ \\
\hline Carotid ultrasonography (2008-2012)§ & $1.07(0.67-1.69)$ & $0.53(0.28-1.00)$ \\
\hline Carotid ultrasonography (2013-2017)§ & $0.89(0.56-1.40)$ & $0.59(0.33-1.06)$ \\
\hline MRI (2003-2007)§ & $1.97(1.07-3.60)$ & $5.25(1.19-23.15)$ \\
\hline MRI (2008-2012)§ & $2.20(1.25-3.88)$ & $4.64(1.09-19.80)$ \\
\hline MRI (2013-2017)§ & $1.99(1.14-3.49)$ & $5.21(1.24-21.84)$ \\
\hline SPECT (2003-2007)§ & $1.61(1.01-2.58)$ & $1.42(0.72-2.78)$ \\
\hline SPECT (2008-2012)§ & $1.21(0.77-1.90)$ & $1.19(0.63-2.24)$ \\
\hline SPECT (2013-2017)§ & $1.24(0.80-1.92)$ & $0.65(0.34-1.24)$ \\
\hline \multicolumn{3}{|c|}{$\begin{array}{l}\text { Note: } \mathrm{Cl}=\text { confidence interval, } \mathrm{CT}=\text { computed tomography, } \mathrm{MRI}=\text { magnetic resonance imaging, SPECT = single-photon } \\
\text { emission computed tomography. } \\
\text { *Estimates are for the 3-month look-back period; Appendix } 3 \text { (Supplementary Tables 5-6; available at www.cmajopen.ca/ } \\
\text { content/8/4/E695/suppl/DC1) provides estimates for each look-back period. } \\
\text { †Total incidentally detected cases shown to obscure back-calculation of positron emission tomography-associated cases, } \\
\text { which were excluded from imaging-specific models because of few cases. } \\
\text { łDenotes a statistical interaction term among the covariates. } \\
\text { §Denotes the statistical interaction estimate among the covariate categories. }\end{array}$} \\
\hline
\end{tabular}


from 1993 to $2004 .{ }^{8}$ We may have detected higher rates of incidental detection among male than female patients because of more intensive screening (thyroid gland ultrasonography and fine-needle aspiration biopsy) for female patients - given higher prevalence of thyroid nodules ${ }^{51}$ and higher age-standardized thyroid cancer rates ${ }^{14}$ - thus defining the cases as nonincidental. However, we believe that using the diagnostic pathway provides an accurate classification of detection given the available population-level data.

\section{Conclusion}

Incidental detection of differentiated thyroid cancer from head, neck and thorax imaging procedures contributes a substantial proportion of cases. Increases in incidentally detected cases are associated with patients having prediagnostic CT scans, which has continued to increase after adjusting for age. Future research on incidentally detected cases should externally validate the classification and evaluate whether patient outcomes are improved (e.g., reduced recurrence), determine which patient and health care system factors are associated with incidental detection, and estimate health care system impacts.

\section{References}

1. Vaccarella S, Franceschi S, Bray F, et al. Worldwide thyroid-cancer epidemic? The increasing impact of overdiagnosis. NEngl 7 Med 2016;375:614-7.

2. Davies L, Welch HG. Increasing incidence of thyroid cancer in the United States, 1973-2002. 7AMA 2006;295:2164-7.

3. Pellegriti G, Frasca F, Regalbuto C, et al. Worldwide increasing incidence of thyroid cancer: update on epidemiology and risk factors. 7 Cancer Epidemiol 2013;2013:965212

4. Noone AM, Howlader N, Krapcho M, et al., editors. SEER Cancer Statistics Review, 1975-2015. Bethesda (MD): National Cancer Institute; 2018.

5. Shaw A, Semenciw R, Mery L. Cancer in Canada Fact Sheet Series \#1 Thyroid cancer in Canada. Chronic Dis Inj Can 2014;34:64-8.

6. Monson JP. The epidemiology of endocrine tumours. Endocr Relat Cancer 2000;7:29-36.

7. Vigneri R, Malandrino P, Vigneri P. The changing epidemiology of thyroid cancer: why is incidence increasing? Curr Opin Oncol 2015;27:1-7.

8. Hall SF, Walker H, Siemens R, et al. Increasing detection and increasing incidence in thyroid cancer. World f Surg 2009;33:2567-71.

9. Brito JP, Morris JC, Montori VM. Thyroid cancer: zealous imaging has increased detection and treatment of low risk tumours. BM7 2013;347:f4706.

10. Sassolas G, Hafdi-Nejjari Z, Remontet L, et al. Thyroid cancer: Is the incidence rise abating? Eur 7 Endocrinol 2009;160:71-9.

11. Valle LA, Kloos RT. The prevalence of occult medullary thyroid carcinoma at autopsy. 7 Clin Endocrinol Metab 2011;96:E109-13.

12. Annual demographic estimates: Canada, provinces and territories, 2018. Ottawa: Statistics Canada; 2019.

13. Canadian Cancer Society's Advisory Committee on Cancer Statistics. Canadian cancer statistics 2017. Toronto: Canadian Cancer Society; 2017.

14. Liu S, Semenciw R, Ugnat AM, et al. Increasing thyroid cancer incidence in Canada, 1970-1996: time trends and age-period-cohort effects. Br 7 Cancer 2001;85:1335-9.

15. Lim H, Devesa SS, Sosa JA, et al. Trends in thyroid cancer incidence and mortality in the United States, 1974-2013. 7AMA 2017;317:1338-48.

16. Kitahara CM, Sosa JA. The changing incidence of thyroid cancer. Nat Rev Endocrinol 2016;12:646-53.

17. Sprague BL, Andersen SW, Trentham-Dietz A. Thyroid cancer incidence and socioeconomic indicators of health care access. Cancer Causes Control 2008;19:585-93.

18. Kent WDT, Hall SF, Isotalo PA, et al. Increased incidence of differentiated thyroid carcinoma and detection of subclinical disease. CMA7 2007;177: 1357-61.

19. Howlader N, Noone AM, Krapcho M, et al., editors. SEER Cancer Statistics Review, 1975-2016. Bethesda (MD): National Cancer Institute; 2019.

20. Ontario cancer statistics 2016. Toronto: Cancer Care Ontario; 2016.

21. Bahl M, Sosa JA, Nelson RC, et al. Thyroid cancers incidentally detected at imaging in a 10-year period: How many cancers would be missed with use of the recommendations from the Society of Radiologists in Ultrasound? Radiology 2014;271:888-94.
22. Malone MK, Zagzag J, Ogilvie JB, et al. Thyroid cancers detected by imaging are not necessarily small or early stage. Thyroid 2014;24:314-8.

23. Hall S, Schulze K, Groome P, et al. Using cancer registry data for survival studies: the example of the Ontario Cancer Registry. 7 Clin Epidemiol 2006;59:67-76.

24. Juurlink D, Preyra C, Croxford R, et al. Canadian Institute for Health Information Discharge Abstract Database: a validation study - ICES Investigative Report. Toronto: Institute for Clinical Evaluative Sciences; 2006.

25. Williams JI, Young W. Appendix 1: A summary of studies on the quality of health care administrative databases in Canada. In: Goel V, Williams JI, Anderson GM, et al., editors. Patterns of health care in Ontario: The ICES Practice Atlas, 2nd edition. Ottawa: Canadian Medical Association; 1996:339.

26. Iron K, Zagorski BM, Sykora K, et al. Living and dying in Ontario: an opportunity for improved health information - ICES Investigative Report. Toronto: Institute for Clinical Evaluative Sciences; 2008.

27. Prodhan S, King MJ, De P, et al. Health services data: the Ontario Cancer Registry (a unique, linked, and automated population-based registry). In: Sobolev $\mathrm{B}$, Levy A, Goring S, editors. Data and measures in health services research. Boston: Springer; 2016:1-27.

28. Rosen MP, Davis RB, Lesky LG. Utilization of outpatient diagnostic imaging. Does the physician's gender play a role? F Gen Intern Med 1997;12:407-11.

29. Wang L, Nie JX, Tracy CS, et al. Utilization patterns of diagnostic imaging across the late life course: a population-based study in Ontario, Canada. Int 7 Technol Assess Health Care 2008;24:384-90.

30. Singer PA, Cooper DS, Daniels GH, et al. Treatment guidelines for patients with thyroid nodules and well-differentiated thyroid cancer. American Thyroid Association. Arch Intern Med 1996;156:2165-72.

31. Cooper DS, Doherty GM, Haugen BR, et al.; American Thyroid Association Guidelines Taskforce. Management guidelines for patients with thyroid nodules and differentiated thyroid cancer. Thyroid 2006;16:109-42.

32. American Thyroid Association (ATA) Guidelines Taskforce on Thyroid Nodules and Differentiated Thyroid Cancer; Cooper DS, Doherty GM, Haugen BR, et al. Revised American Thyroid Association management guidelines for patients with thyroid nodules and differentiated thyroid cancer. Thyroid 2009; 19:1167-214.

33. Haugen BR, Alexander EK, Bible KC, et al. 2015 American Thyroid Association management guidelines for adult patients with thyroid nodules and differentiated thyroid cancer: The American Thyroid Association Guidelines Task Force on Thyroid Nodules and Differentiated Thyroid Cancer. Thyroid 2016;26:1-133.

34. Le AR, Thompson GW, Hoyt BJA. Thyroid fine-needle aspiration biopsy: an evaluation of its utility in a community setting. F Otolaryngol Head Neck Surg 2015;44:12.

35. Ghai S, Lee SY, Bret PM, et al. Thyroid biopsy specialists: a quality initiative to reduce wait times and improve adequacy rates. Radiology 2015;276:894-9.

36. Table 17-10-0005-01: Population estimates on fuly 1st, by age and sex. Ottawa: Statistics Canada; modified 2020 June 17. Available: www150.statcan.gc.ca/t1/ tbl1/en/tv.action?pid=1710000501 (accessed 2020 May 05).

37. Joinpoint Regression Program. Version 4.7.0.0. Bethesda (MD): Statistical Research and Applications Branch, National Cancer Institute; 2019.

38. Hilbe JM. Modeling count data. Cambridge (UK): Cambridge University Press; 2014.

39. Yang Y, Fu WJ, Land KC. A methodological comparison of age-period-cohort models: the intrinsic estimator and conventional generalized linear models. Sociol Methodol 2004;34:75-110. doi: 10.1111/j.0081-1750.2004.00148.x.

40. The DOE Ionizing Radiation Dose Ranges Chart [information brief]. Washington (DC): Office of Environment, Health, Safety and Security; 2017.

41. Toyoda Y, Tabuchi T, Nakata K, et al. Increase in incidental detection of thyroid cancer in Osaka, Japan. Cancer Sci 2018;109:2310-4.

42. Zheng T, Holford TR, Chen Y, et al. Time trend and age-period-cohort effect on incidence of thyroid cancer in Connecticut, 1935-1992. Int 7 Cancer 1996;67:504-9.

43. National survey of selected medical imaging equipment, CIHI, 2012. Ottawa: Canadian Institute of Health Information; 2013.

44. Ontario cancer statistics 2018. Toronto: Cancer Care Ontario; 2018.

45. Hundahl SA, Cady B, Cunningham MP, et al.; U.S. and German Thyroid Cancer Study Group. Initial results from a prospective cohort study of 5583 cases of thyroid carcinoma treated in the united states during 1996: an American College of Surgeons Commission on Cancer patient care evaluation study. Cancer 2000;89:202-17.

46. Filho JG, Kowalski LP. Postoperative complications of thyroidectomy for differentiated thyroid carcinoma. Am $\mathcal{F}$ Otolaryngol 2004;25:225-30.

47. Carballo M, Quiros RM. To treat or not to treat: the role of adjuvant radioiodine therapy in thyroid cancer patients. F Oncol 2012;2012:707156.

48. Van Nostrand D. The benefits and risks of I-131 therapy in patients with well-differentiated thyroid cancer. Thyroid 2009;19:1381-91.

49. Wu JX, Young S, Ro K, et al. Reproductive outcomes and nononcologic complications after radioactive iodine ablation for well-differentiated thyroid cancer. Thyroid 2015;25:133-8.

50. US Preventive Services Task Force; Bibbins-Domingo K, Grossman DC, Curry SJ, et al. Screening for thyroid cancer: US Preventive Services task force recommendation statement. FAMA 2017;317:1882-7.

51. Vander JB, Gaston EA, Dawber TR. The significance of nontoxic thyroid nodules. Final report of a 15-year study of the incidence of thyroid malignancy. Ann Intern Med 1968;69:537-40. 
Affiliations: Dalla Lana School of Public Health (Norwood, Buajitti, Rosella), University of Toronto; Cancer Care Ontario (Norwood); Women's College Hospital (Lipscombe); Institute of Health Policy, Management and Evaluation (Lipscombe, Stukel), University of Toronto; ICES Central (Stukel, Rosella), Toronto, Ont.

Contributors: Todd Norwood identified the knowledge gap and designed an initial study protocol and analytic approach. Todd Norwood, Lorraine Lipscombe, Thérèse Stukel and Laura Rosella contributed to the study design and analytic approach. Todd Norwood and Emmalin Buajitti have ongoing access to the study data. Emmalin Buajitti linked the administrative data sources to create the study cohort; Todd Norwood conducted the descriptive and statistical analyses and drafted the manuscript. All authors contributed to the interpretation of the findings, and reviewed and edited the manuscript. All authors gave final approval of the version to be published and agreed to be accountable for all aspects of the work.

Funding: This study was funded by a Doctoral Research Award (Frederick Banting and Charles Best Canada Graduate Scholarship) from the Health Services and Policy Research Institute, Canadian Institutes of Health Research. The funder was not involved in the study design, conduct, analyses or publication.
Data sharing: The data set from this study is held securely in coded form at ICES. While data sharing agreements prohibit ICES from making the data set publicly available, access may be granted to those who meet pre-specified criteria for confidential access, available at https://www.ices.on.ca/DAS. The full data set creation plan and underlying analytic code are available from the authors upon request, understanding that the programs may rely upon coding templates or macros that are unique to ICES.

Supplemental information: For reviewer comments and the original submission of this manuscript, please see www.cmajopen.ca/content/8/4/ E695/suppl/DC1.

Disclaimer: This study was supported by ICES, which is funded by an annual grant from the Ontario Ministry of Health and Long-Term Care (MOHLTC). The opinions, results and conclusions reported in this paper are those of the authors and are independent from the funding sources. No endorsement by ICES or the Ontario MOHLTC is intended or should be inferred. All data sets used in this study were linked using unique encoded identifiers and analyzed at ICES. Parts of this material are based on data and/or information compiled and provided by the Canadian Institute for Health Information (CIHI). However, the analyses, conclusions, opinions and statements expressed in the material are those of the author(s), and not necessarily those of CIHI. 